\title{
Physico-chemical, Morphological and Pasting Properties of Starches Extracted from Water Chestnuts (Trapa natans) from Three Lakes of Kashmir, India
}

\author{
Adil Gani $^{1 *}$, Sham Sul Haq ${ }^{2}$, F.A. Masoodi ${ }^{1}$, A. A. Broadway ${ }^{2}$ and Asir Gani ${ }^{3}$ \\ ${ }^{1}$ Department of Food Technology; University of Kashmir; Hazratbal Srinager; JandK - India.$^{2}$ Department of Food \\ and Dairy Technology; Allahabad Agricultural Institute; University Allahabad (UP); India . ${ }^{3}$ Department of Food \\ Technology; Islamic University of Science and Technology; Awantipora - JandK - India
}

\begin{abstract}
Studies on physicochemical, morphology and pasting properties of starches extracted from water chestnuts of three Lakes of Kashmir valley (Wular, Anchar and Dal Lakes) were conducted to determine their application in different food products. The water chestnut starch from Dal Lake had more oval shaped granules than water chestnut starches from the Wular and the Anchar Lakes.The unique feature of the water chestnut starches were shape of starch granules which looked like horn(s) protruding from the surface which did not appear in other starches already studied. Proximate analysis of water chestnut starches showed that average protein content were $0.4 \%$, amylose $29.5 \%$ and ash 0.007 on dry weight basis. Increase in water binding capacity, swelling power and solubility was found over a temperature range of $50-90^{\circ} \mathrm{C}$. Water chestnut starches showed an increase in syneresis during freeze thaw cycles and decline in paste clarity upon storage. Starch extracted from the water chestnuts of the Dal Lake showed higher water binding capacity, swelling, solubility, past clarity, freeze thaw stability, peak viscosity, final viscosity and lower protein content, amylose content, pasting temperature and gel firmness than starches extracted from water chestnuts of the Wular and the Anchar Lakes.
\end{abstract}

Key words: Water chestnut, Morphology, Physioco-chemical properties, Pasting properties, Gel Texture

\section{INTRODUCTION}

The Asian water chestnut (Trapa natans), locally called as Guar in Jammu and Kashmir, India, belongs to the monogeneric family Trapaceae and is an invasive aquatic plant that is slowly, but inexorably, spreading throughout the Lakes of Kashmir valley. The interesting features of Guar are the color and shape of its outer cover in which the kernel is encased, the water chestnut (Fig.1) is covered with a thick jet-black outer cover shaped like a horn protruding from the head of a buffalo.
The outer cover is hard, making it quite difficult to peel off to obtain the white meat (edible portion) inside. The common method for preparing Guar is by steaming to softer the outer cover and at the same time, cook the inside meat. The meat is usually eaten as snacks or used as an ingredient in the preparation of other food products. Composition of the water chestnuts reveals starch as the main component. Starch as a raw material has various applications in the manufacturing of food products like imparting texture and consistency, and acts as functional ingredients like

*Author for correspondence: adil.gani@gmail.com 
thickeners, stabilizers and gelling agent. The annual worldwide production of starch is 66.5 millions tons (FAOSTAT, 2002). Growing demand for starches in the food industry has created interest in new sources of this polysaccharide. The most important properties to consider when determining starch uses in food systems and other industrial applications are physicochemical (e.g. gelatinization and retrogradation) and functional (e.g. solubility, swelling, water absorption, syneresis and rheological behaviour of pastes and gels) (Wang and White, 1994). A fundamental characteristic of native starches from different vegetal sources is that their granule and molecular structures influence their physicochemical and functional properties. The most significant sources of starch are cereal grains, such as corn, wheat and rice and tubers, such as potato and cassava. The thickening power of starches makes them useful in food and industrial applications. Studies on the use of nonconventional source of starch have been documented by Moorthy (2002), describing the clarity and good gel strength of cassava (Manihot esculenta) as useful in wide range of food products. The present study is on the use of nonconventional starch from water chestnut ( $T$. natans) found in three Lakes (Dal Lake, Wular Lake, Anchar Lake ) of Kashmir (India).

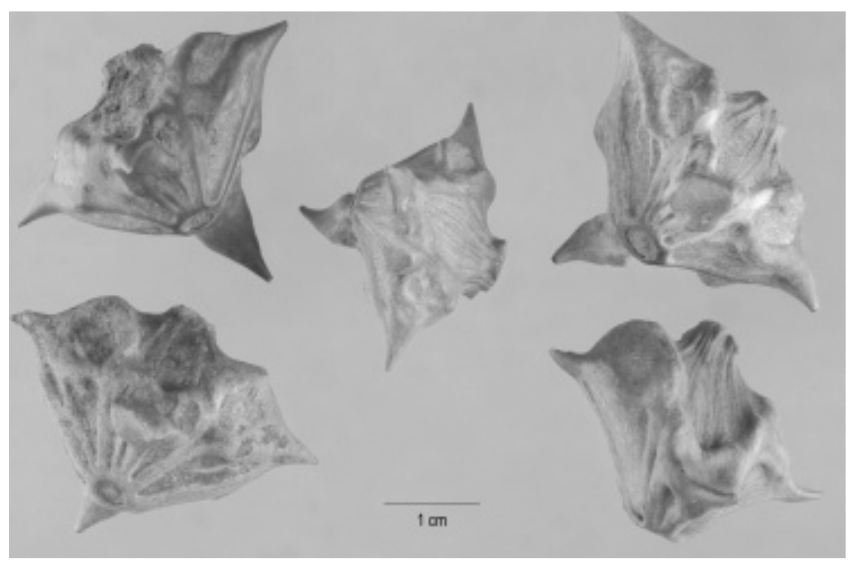

Figure1 - Guar (Trapa natans).

\section{MATERIAL AND METHODS}

\section{Sources of water chestnuts and sample preparation}

The water chestnuts (Trapa natans) used in this study were collected from three Lakes of Kashmir. Each sample uniform in size, shape and free from foreign agents was washed with clean water and stored at $5^{\circ} \mathrm{C}$ till use.

\section{Starch Extraction}

Water chestnut starches were extracted by the method of Vanna et al., (2004). They were graded in order to obtain the fruits of the same size. The selected fruits were peeled, washed and cut into small pieces. Representative samples of $1 \mathrm{~kg}$ were ground in a blender with $2 \mathrm{~L}$ of $0.2 \%$ sodium hydroxide solution. The slurry was filtered through 100- and 200-mesh sieves and centrifuged at 1000×g (Heraeus-Christ, Germany). The sediment was resuspended with two volumes of water and centrifuged again. The washing steps were repeated until the supernatant was clear and the starch was free of color. The starch was then dried in an air oven at $45 \pm 1^{\circ} \mathrm{C}$ until the moisture content was less than $13 \%$.

\section{Morphology of the Starch Granules}

Scanning electron micrographs (SEM) of water chestnut starches were obtained using a scanning electron microscope (Model ABT-150S, Topon Corp., Japan). Isolated starches were sprinkled on double-sided adhesive tape fixed on an aluminium stub. The sample was coated with a goldpalladium (Model JBS-ES 150, Ion sputter coater, Topon Corp., Japan). An accelerating potential of $15 \mathrm{kV}$ was used during electron microscopy in this study 


\section{Physicochemical properties \\ Chemical Analysis}

Moisture, lipid, crude protein and ash contents were determined according to standard methods of AACC (1995). Starch content was determined using the AOAC (1995) Polarimetric method. The apparent amylose content was estimated by the six point wave length spectrophotometric analysis by Javis and Walker (1993).

\section{Color}

Colors of starches were determination using color flex spectrocolorimeter, (Model no. 45/0, CX1075, Hunter Lab Reston, VA, USA, 2002) after being standardized using Hunter lab color standards. The parameters recorded were $\mathrm{L}$, $\mathrm{a}$ and $\mathrm{b}$ co-ordinates of the CIE scale.

\section{Water absorption capacity}

Water retention was determined as described by Hallgren (1985). 5 gram of starch and $100 \mathrm{ml}$ of water was added to pre-weighed centrifuge tubes at room temperature and then heated to different temperatures, i.e.; $50,60,70,80$, and $90^{\circ} \mathrm{C}$, for 15 $\mathrm{min}$. with every $5 \mathrm{~min}$ shaking period. Tubes were centrifuged at $3000 \times \mathrm{g}$ for $15 \mathrm{~min}$., the supernatant was decanted, and the tubes were allowed to drain for $10 \mathrm{~min}$. at a $45^{\circ}$ angle. The tubes were then weighed and the gain in weight was used to calculate the water retention capacity.

\section{Swelling power and starch solubility}

Starches of five suspensions $(1 \%, \mathrm{w} / \mathrm{w})$ was prepared in a flask, heated to $50,60,70,80$, and $90^{\circ} \mathrm{C}$ for $30 \mathrm{~min}$. with shaking every $5 \mathrm{~min}$ and left for cooling to room temperature and centrifuged for $15 \mathrm{~min}$ at $3000 \times \mathrm{g}$. The supernatant was decanted and the residual volume was determined. The solid part was dried in an oven for $2 \mathrm{~h}$ at $130^{\circ} \mathrm{C}$

\section{Paste clarity}

Starch suspensions $(4 \%, \mathrm{w} / \mathrm{w})$ in screw cap tube were placed in boiling water for $30 \mathrm{~min}$. and thoroughly shaken for every $5 \mathrm{~min}$. After cooling to room temperature, some samples were refrigerated to $6^{\circ} \mathrm{C}$ for $72 \mathrm{~h}$ and every $24 \mathrm{~h}$ transmition at $650 \mathrm{~nm}$ was determined against water as blank. (Perkin Elmer Lambda Bio 2.3 spectrophotometer).

\section{Freeze-thaw stability}

Aqueous suspensions $(5 \mathrm{ml})$ of starches $(5 \% \mathrm{w} / \mathrm{v})$ were rapidly heated about 90 seconds to previously determined gelatinization temperature under constant agitation. These suspensions were then held at $30 \mathrm{~min}$. before being cooled. The gels were subjected to cold storage at $-20^{\circ} \mathrm{C}$ for $18 \mathrm{~h}$ and thawed to $28^{\circ} \mathrm{C}$ for $6 \mathrm{~h}$. The exuded water was determined gravimetrically by vortexing the thawed gels for 15 seconds followed by centrifugation at $3000 \times \mathrm{g}$ for $10 \mathrm{~min}$. (Bello-Perez et al., 1999). The percentage of water separated after each freeze-thaw cycle was measured and expressed as the percentage of water separated.

\section{Starch pasting}

In all cases, samples for RVA analysis were based on $3.5 \mathrm{~g}$ (dry weight) of starch plus distilled water $(25 \mathrm{~g})$. The paddle was placed into the canister containing the sample and water. The paddle blade was vigorously jogged through the sample up and down seven times. The sample was then inserted in the Rapid Visco Analyzer (Model: RVA, Newport Scientific pty. Ltd., Sydney, Australia, 1994). The RVA analysis was done by standard Profile 1. The parameters recorded from the pasting profile were Peak viscosity (PV), Final viscosity and Pasting temperature.

\section{Starch gel firmness}

The pastes from the RVA experiments were kept in the RVA canisters, sealed and kept at $5^{\circ} \mathrm{C}$ for 24 h. The starch gels were then taken out of the canister and were cut into $15 \times 15 \times 15 \mathrm{~mm}$ blocks. Texture analysis of the gels were determined using TAX2- Texture analyzer (Stable Microsystems, UK). The gels were compressed at a crossed head speed of $0.8 \mathrm{~mm} / \mathrm{sec}$ with a cylindrical probe (40mm dia.) under the texture profile analysis (TPA) test mode. Peak force of the first penetration was termed gel strength. Measurements were made, in triplicate. 


\section{RESULTS AND DISCUSSION}

\section{Morphology of water chestnut starches}

The appearances of native water chestnut starches from three different lakes are shown in Fig. 2. The surfaces of the granules of all samples were smooth with no evidence of cracks. Upon magnification $(1000 \mathrm{x})$, some granules appeared to be either round or oval in shape with "horn(s)" protruding from the surface.

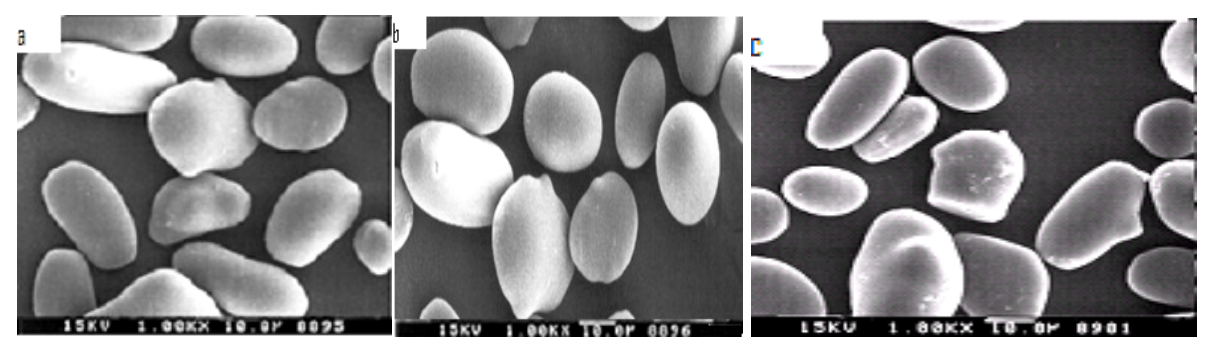

Figure 2 - Guar Starch granules extracted from (a) Dal starch (b) Wular starch (c) Anchar starch.

This was a unique feature which did not appear in other starches already studied. The water chestnut starch from the Dal Lake had more oval shaped granules than water chestnut starches from the Wular and the Anchar Lakes. Water chestnut starch from the Dal Lake also showed the presence of many large-sized granules, followed by that from the Wular Lake and the Anchar Lake. Thus, the results showed that the water chestnut starches from the different lakes had different appearances of granules. The different sizes and shapes of starch granules affect their physicochemical characteristics such as amylose content, gelatinization temperature, pasting properties, etc.

\section{Physicochemical properties}

Chemical Composition of the Starch

Data of general analysis are shown in Table 1. The starches obtained from water chestnuts of three Lakes showed protein and ash content less than $1 \%$. Water chestnut starch from the Dal Lake had lower protein $(0.11 \%)$ and ash $(0.006 \%)$ than that from the Lakes of Wular and Anchar, indicating its high purity. These values were similar to those of cassava starch (Moorthy, 2002). Because of its low protein content $(0.11 \%)$, water chestnut starch from the Dal Lake could be used in the manufacture of high glucose syrups as its protein level was lower than FDA protein content limits for corn starch $(0.4 \%)$ used for this purpose. It was found that starch content also varied among the water chestnut cultivars, ranging from $80-97.4 \%$. It indicated that these water chestnut cultivars could be a good source of carbohydrate. Amylose content was highest in water chestnut starch from the Anchar Lake $(30.5 \%)$, followed by that from the Wular Lake $(29.6 \%)$ and from the Dal Lake $(28.5 \%)$. This was higher than that of the water chestnut $T$. natans L. var. bispinosa Makino starch (23\%) (Hizukuri et al., 1988). and of water chestnut T. bispinosa Roxb. starch (15\%) (Murty et al., 1962).

Table 1 - Chemical Composition of starches extracted from water chestnut.

\begin{tabular}{cccccc}
\hline Starch & $\mathbf{M \%}$ & $\mathbf{C P \% \dagger}$ & $\mathbf{A h \% \dagger}$ & $\mathbf{S \%} \dagger$ & $\mathbf{A \%} \dagger$ \\
\hline Wular & 9.5 & 0.5 & .007 & 85 & 29.6 \\
Anchar & 10.5 & 0.6 & 0.008 & 80 & 30.6 \\
Dal & 8.3 & 0.11 & 0.006 & 97.4 & 28.5
\end{tabular}

Moisture (M), Crude Protein (CP), Ash (Ah), Starch (S), Amylose (A)

* Mean of four replicates.

$\dagger$ Dry weight basis. 


\section{Color}

Color analysis showed "L" values in the range of 80.89 to 88.68 , "a" 0.15 to 1.74 and "b" 2.81 to 3.89 (Table 2). The color of starch due to the presence of polyphenolic compounds, ascorbic acid and carotene has impact on its quality. Any pigmentation in the starch is carried over to the final product. This reduces the quality, hence acceptability of starch product (Galvez and Resurreccion, 1992). A low value for chroma and a high value for lightness are desired for the starch to meet the consumer preference. Water chestnut starch from the Dal Lake was the best in terms of starch color, with the highest value of whiteness $(\mathrm{L}=88.68)$ and lower value of chroma $(\mathrm{a}=0.15)$ than water chestnut starch from the Wular and the Anchar Lakes, while water chestnut starch from the Anchar Lake had lowest whiteness value ( $\mathrm{L}$ $=80.89$ ) and highest value of chroma $(\mathrm{a}=1.7)$. Thus, in this study, color of water chestnut starch isolated from the Dal lake met the consumer preference due to the highest whiteness and lower chroma values.

Table 2 - Color Analysis of water chestnut starch.

\begin{tabular}{cccc}
\hline Starch & & Color values & $\mathrm{b}$ \\
Wular & $\mathrm{L}$ & $\mathrm{a}$ & $3.4 \pm 2.1$ \\
Anchar & $85.28 \pm 2.8$ & $0.25 \pm 0.23$ & $3.89 \pm 2.3$ \\
Dal & $80.89 \pm 5.1$ & $1.7 \pm 0.1$ & $2.81 \pm 1.4$
\end{tabular}

L- Lightness (black/white), a-chroma (green/red) and b-hue (blue/yellow).

$\pm \mathrm{SD}=$ Standard deviation; Mean of three replicates.

\section{Water binding capacity}

Variations was found in water binding capacity among the water chestnut starches. Water binding pattern (Fig:3) showed that with increase in temperature over a temperature range of $50-90^{\circ} \mathrm{C}$, water binding capacity had a tendency to increase and the results ranged from 13 to $60 \%, 9$ to $52 \%$ and 7 to $44 \%$ for water chestnut starches from the Dal, the Wular and the Anchar Lakes, respectively. The highest results were obtained with water chestnut starch from the Dal Lake and lowest with water chestnut from the Anchar Lake. Low water binding capacity of starches could be attributed to the involvement of a larger proportion of the hydroxyl groups in forming hydrogen and covalent bonds between the starch chains than with water (Hoover and Sosulski, 1986). Water chestnut starches has shown almost the same water binding capacity as macho and criollo banana starches (Bello-Perez et al., 1999).

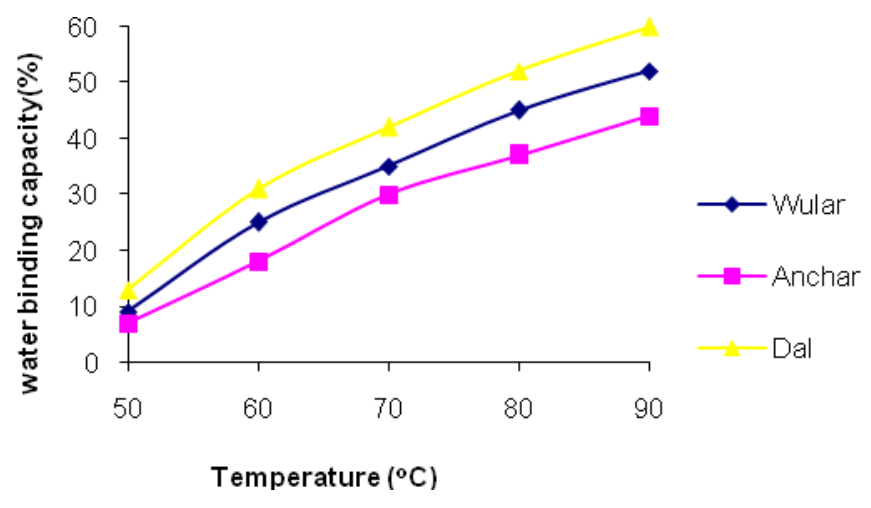

Figure 3 - Water binding capacity of water chestnut starches submitted to heat from 50 to $90^{\circ} \mathrm{C}$. 


\section{Swelling power and starch solubility}

When aqueous suspensions of starch granules are heated, the starch molecule hydrates and swells with a consequent leaching of some soluble starch into the liquid. Swelling power and solubility are characteristics of the starch. The swelling power of water chestnut starches were measured at $10^{\circ} \mathrm{C}$ intervals over a temperature range of 50 to $90^{\circ} \mathrm{C}$ (Table 3). The results indicated that water chestnut starch of the Anchar Lake had fairly restricted swelling power ranging from (1.4 to11\%) compared to water chestnut starch of the Wular Lake (2.2 to15\%) and highest for water chestnut starch of the Dal Lake (4.2-18.3\%). Water chestnut starch of the Dal Lake also showed highest solubility in the range of (3.4 to17\%) when compared with water chestnut starch of the Wular Lake (1.4-14.4\% ) and water chestnut starch of the Anchar Lake (0.4-10\%) over a temperature range of $50-90^{\circ} \mathrm{C}$. Solubility and swelling power in water chestnut starches of three lakes were directly influenced by the temperature. The swelling pattern (Fig. 4) showed that at the temperatures lower than $70^{\circ} \mathrm{C}$, the water chestnut starch granules resisted the swelling, probably due to their high initial gelatinization temperature. From 70 to $90^{\circ} \mathrm{C}$, the granules gradually swelled as temperature increased, as a result of intermolecular hydrogen bridge rupture in the amorphous areas, which allowed irreversible and progressive water absorption. Similar rapid increases have been reported for T. natans L. var. bispinosa makino starch (Hizukuri et al., 1988) in the temperature range of $60-80^{\circ} \mathrm{C}$. Swelling similar to that of water chestnut starches has been reported by Gujska et al., (1994) for pinto bean and navy bean starches, in which swelling also increased rapidly beginning at $70^{\circ} \mathrm{C}$. The solubility change followed the same trend as the swelling power (Fig.5).

Table 3 - Swelling power of water chestnut starches submitted to heat from $50{ }^{\circ} \mathrm{C}$ to $90{ }^{\circ} \mathrm{C}$.

\begin{tabular}{cccccc}
\hline starch & \multicolumn{5}{c}{ Swelling power\% } \\
\hline Wular & $\mathbf{5 0}^{\mathbf{0}} \mathbf{C}$ & $\mathbf{6 0}^{\mathbf{0}} \mathbf{C}$ & $\mathbf{7 0}^{\mathbf{0}} \mathbf{C}$ & $\mathbf{8 0}^{\mathbf{0}} \mathbf{C}$ & $\mathbf{9 0}^{\mathbf{0}} \mathbf{C}$ \\
Anchar & $2.2 \pm 0.2$ & $3.0 \pm 0.2$ & $5.0 \pm 0.4$ & $9.2 \pm 0.5$ & $15 \pm 0.6$ \\
Dal & $1.4 \pm 0.1$ & $2.0 \pm 0.2$ & $2.9 \pm 0.1$ & $7.0 \pm 0.5$ & $11 \pm 0.4$ \\
\hline
\end{tabular}

Mean of three replicates.

$\pm \mathrm{SD}=$ Standard deviation

Table 4- solubility of water chestnut starches submitted to heat from $50{ }^{0} \mathrm{C}$ to $90{ }^{\circ} \mathrm{C}$.

\begin{tabular}{cccccc}
\hline starch & \multicolumn{5}{c}{ Solubility \% } \\
\hline Wular & $\mathbf{5 0}^{\mathbf{0}} \mathbf{C}$ & $\mathbf{6 0}^{\mathbf{0}} \mathbf{C}$ & $\mathbf{7 0}^{\mathbf{0}} \mathbf{C}$ & $\mathbf{8 0}^{\mathbf{0}} \mathbf{C}$ & $\mathbf{9 0}^{\mathbf{0}} \mathbf{C}$ \\
Anchar & $1.4 \pm 0.8$ & $2.3 \pm 0.7$ & $3.1 \pm 1.3$ & $7.3 \pm 0.7$ & $14 \pm 0.4$ \\
Dal & $0.4 \pm 0.1$ & $1 \pm 0.2$ & $2.1 \pm 0.2$ & $5.0 \pm 0.3$ & $10 \pm 0.5$ \\
& $3.4 \pm 0.1$ & $4.4 \pm 0.1$ & $5.4 \pm 0.7$ & $10 \pm 0.4$ & $17 \pm 0.5$ \\
\hline
\end{tabular}

Mean of three replicates.

$\pm \mathrm{SD}=$ Standard deviation

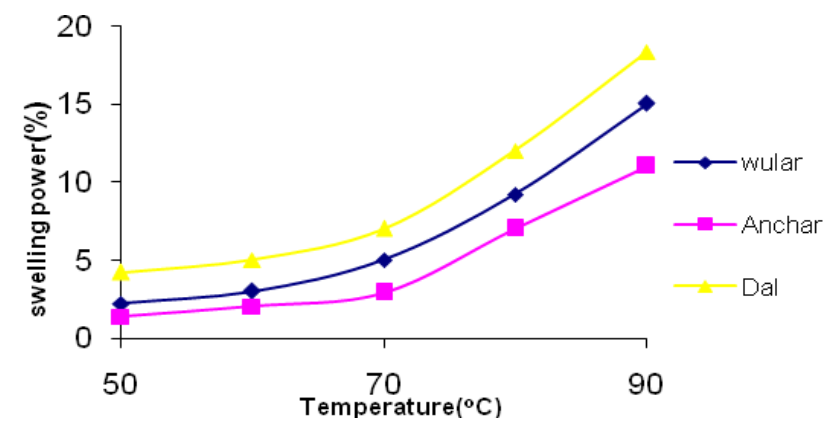

Figure 4 - swelling power of water chestnut starches submitted to heat from 50 to $900 \mathrm{C}$. 


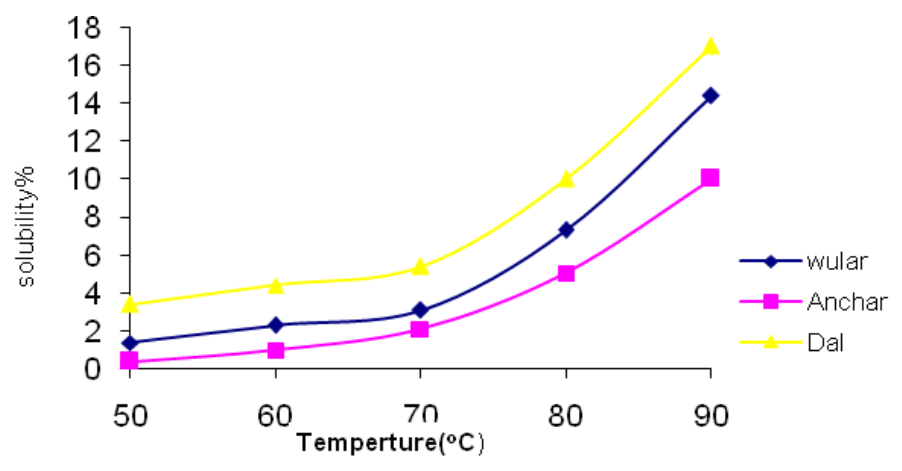

Figure 5 - Solubility of water chestnut starches submitted to heat from 50 to 90 0C.

\section{Paste clarity}

Differences in paste clarity were observed between the water chestnut starches from three lakes (Table 5). Water chestnut starch from the Dal Lake showed improved paste clarity when compared with water chestnut starch from the Wular and the Anchar lakes which could be because of variation in water penetration and absorption of the starch granules, which ultimately led to difference in swelling of starch and resulting in more or less transmittance of light (Craig et. al., 1989). However, no such trend was observed with all types of starches, for example amaranth starch (Bhandari and Singhal, 2002). Fact that the starch paste degree of transmittance is directly affected by degree of swelling,this coincided with the present result in that the water chestnut starch from the Dal Lake had greater swelling power and higher clarity in its paste than that of water chestnut starch from the Wular Lake and the Anchar Lake. The water chestnut starch from Dal Lake showed higher paste transmittance than water chestnut starch from the Wular and the Anchar Lakes because of greater clarity of its amylase content (Swinkels, 1985). The influence of storage days on paste clarity of starches was also determined. In all the starches, percent transmittance was reduced as the number of days of storage increased. Similar time-dependent reduction in transmittance has been reported for banana starch (Bello-Perez et al., 2000).

Table 5 - Effect of storage on paste clarity of water chestnut starches.

\begin{tabular}{lcccc}
\hline starch & \multicolumn{4}{c}{ \%transmittance } \\
\hline Hours & $\mathbf{0}$ & $\mathbf{2 4}$ & $\mathbf{4 8}$ & $\mathbf{7 2}$ \\
\hline Wular & $2.5 \pm 0.1$ & $2.2 \pm 0.6$ & $1.4 \pm 0.1$ & $0.5 \pm 0.05$ \\
Anchar & $1.5 \pm 0.05$ & $0.8 \pm 0.05$ & $0.6 \pm 0.1$ & $0.3 \pm 0.05$ \\
Dal & $2.8 \pm 0.05$ & $2.5 \pm 0.1$ & $1.9 \pm 0.05$ & $0.8 \pm 0.05$ \\
\hline
\end{tabular}

Mean of three replicates.

$\pm \mathrm{SD}=$ Standard deviation.

\section{Freeze-thaw stability}

Water chestnut starch from the Dal Lake showed better stability and less syneresis than water chestnut starch from the Wular and the Anchar Lakes in all freeze thaw cycles (Fig.6). The amount of water separated from the gels increased with storage time. Baker and Rayas-Duarte (1998) have reported this behavior for corn starches, mentioning low freeze-thaw gel stability for corn and amaranth starches. Likewise, Bello-Perez et al., (1999) found low gel stability in the same processes for banana starch. Low gel stability under these conditions suggests it is not convenient for use in food systems involving refrigeration or freezing processes. 


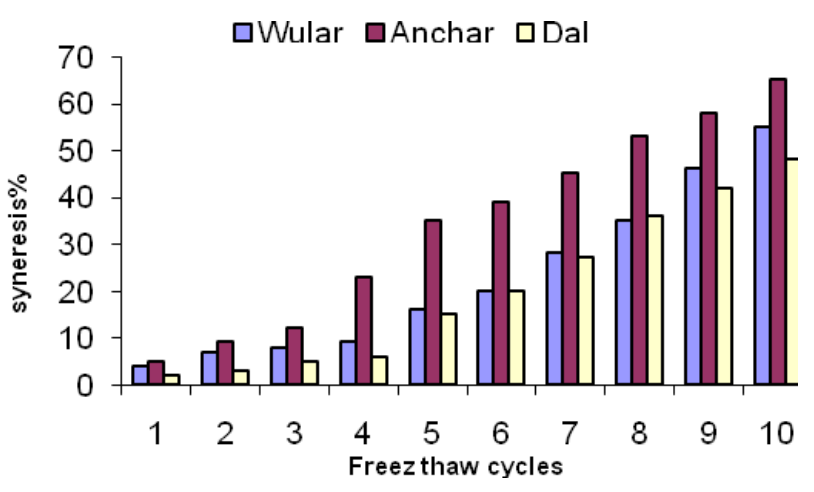

Figure 6 - Freeze thaw stability of water chestnut starches.

\section{Pasting properties}

Pasting properties of water chestnut starches are shown in Table 6. Water chestnut starches showed gradual increase in viscosity with increase in temperature (Fig.7). The increase in viscosity with temperature could be attributed to the removal of water from the exuded amylose by the granules as they swelled (Ghiasi et al., 1982). Peak viscosity (PV) for water chestnut starches ranged between 2719 to $3714 \mathrm{cP}$, the lowest for water chestnut starch of the Anchar Lake and the highest for water chestnut starch of the Dal Lake. Final viscosity (FV) (indicated the ability of the starch to form a viscous paste) for water chestnut starches ranged from 3323 to $4385 \mathrm{cP}$, the lowest shown by water chestnut starch of the Anchar Lake and the highest by water chestnut starch of the Dal Lake. Miles et al., (1985) reported that increase in final viscosity might be due to the aggregation of the amylose molecules. Pasting properties are dependent on the rigidity of starch granules, which in turn affects the granule swelling potential (Sandhya Rani and Bhattacharaya, 1989) and amount of amylase leaching out in the solution (Morris, 1990). Pasting temperature for water chestnut starches ranged between 71.4 to $84^{\circ} \mathrm{C}$, the lowest shown by water chestnut starch from the Dal Lake and the highest by water chestnut starch of the Anchar Lake. The high pasting temperature of water chestnut starches of the Anchar Lake $\left(84^{\circ} \mathrm{C}\right)$ and Wular Lake $\left(81^{\circ} \mathrm{C}\right)$ than water chestnut starch of the Dal Lake $\left(71.4^{\circ} \mathrm{C}\right)$ indicated their more resistance towards swelling. Seetharaman et al., (2001) reported pasting temperatures in the range of 74.9 to $84.7^{\circ} \mathrm{C}$ for Argentinian corn landraces.

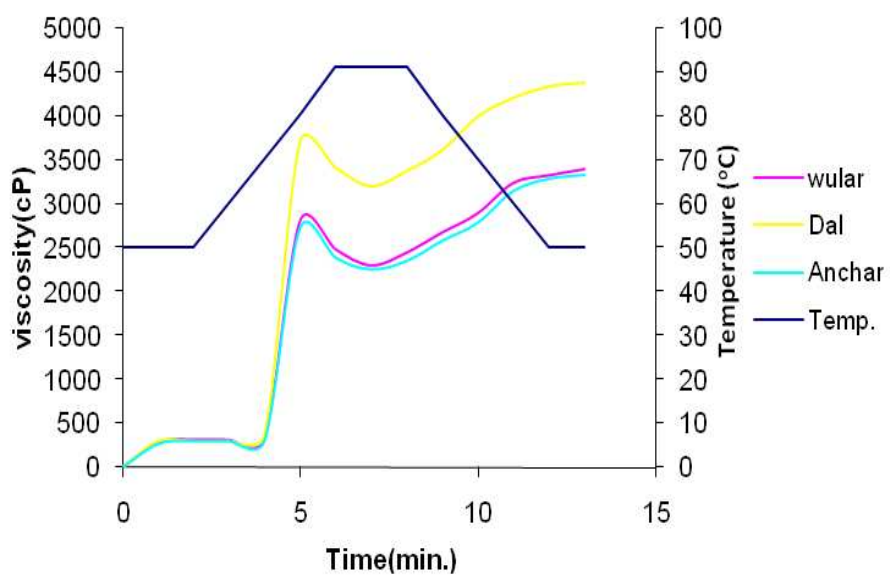

Figure 7 - pasting profile of water chestnut starches. 
Table 6 - Pasting Parameters and Gel firmness.

\begin{tabular}{lcccc}
\hline starch & Peak viscosity & Final viscosity & Pasting Temp. & GCPF(g) \\
\hline Wular & $2808 \pm 0.5$ & $3394 \pm 1.1$ & $81 \pm 2.6$ & $30 \pm 2$ \\
Anchar & $2719 \pm 1.1$ & $3323 \pm 2.8$ & $84 \pm 1.0$ & $39 \pm 1.2$ \\
Dal & $3714 \pm 1.1$ & $4382 \pm 2$ & $71.4 \pm 1.4$ & $27 \pm 0.7$ \\
\hline
\end{tabular}

Mean of three replicates.

$\pm \mathrm{SD}=$ Standard deviation

$\mathrm{GCPF}=\mathrm{Gel}$ compression peak force in grams.

\section{Gel Firmness}

The firmness of starch gels from water chestnut starches of three lacks are shown in Table 6 . Starch gel from water chestnut starch from the Anchar Lake showed the highest hardness (39g), water chestnut starch from the Wular Lake the intermediate $(30 \mathrm{~g})$ and water chestnut starch from the Dal Lake the lowest hardness (27g) Seetharaman et al., (2001) reported the hardness of 13 selected Argentinian corn landraces in the range between 16.7 and $35 \mathrm{~g}$. The gel firmness is mainly caused by retrogradation of starch gels, which is associated with the syneresis of water and crystallization of amylopectin, leading to harder gels (Miles et al., 1985). Starches that exhibit harder gels tend to have higher amylose content and longer amylopectin chains (Mua and Jackson, 1997).

\section{CONCLUSION}

Variation in the physicochemical, morphological, pasting and gel texture properties of water chestnut starches extracted from three lacks were observed. The SEM of water chestnut starch granules revealed that the surfaces were smooth with no evidence of cracks. Upon magnification, some granules appeared to be either round or oval in shape with "horn(s)" protruding from the surface; this is a unique feature which does not appear in other starches already studied. The pasting properties indicate that thickening is stable in cooking processes. Water chestnut starch from the Dal Lake showed higher swelling power, peak and final viscosities than water chestnut starch from the Wular and the Anchar Lakes together with its water absorption, swelling power and solubility values which showed an increase with increasing temperature making it potentially useful in products subjected to higher temperatures, such as canned foods, baby food, sauces, bread products, jellies, candies and sausages. Water chestnut starch from the Dal Lake also showed low crude protein content which would make it useful in the manufacture of high-glucose syrups. The unique characteristics of these starches indicate its potential to be used as an ingredient for the preparation of a variety of food products.

\section{ACKNOWLEDGEMENTS}

Authors acknowledge the Department of Food Technology, Government Women Polytechnic, Srinagar for allowing to use their Laboratory.

\section{REFERENCES}

AACC. (1995), Approved Methods of the AACC. American Association of Cereal Chemists, St. Paul, $\mathrm{MN}$.

AOAC. (1995), Official Methods of Analysis, 16th Ed., Association of Official Analytical Chemists, Washington, DC.

Baker, L. A.; Rayas-Duarte, O.(1998), Freeze-thaw stability of amaranth starch and the effects of salts and sugars. Cereal Chemistry, 75, 301-307.

Bello-Perez, L. A., Agama-Acevedo, E., SanchezHernandez, L., Paredes-Lopez, O. (1999), Isolation and partial characterization of banana starches. Journal of Agricultural and Food Chemistry, 47, 854-857.

Bello-Perez, L. A., Romero-Manilla, R., ParedesLopez, O. (2000), Preparation and properties of physically modified banana starch prepared by alcoholic alkaline treatment. Starch, 52, 154-159.

Bhandari, P. N., Singhal, R. S. (2002), Effect of succinylation on the corn and amaranth pastes. Carbohydrate Polymers, 48, 233-240.

Craig, S. A. S., Maningat, C. C., Seib, P. A., Hoseney, R. C. (1989), Starch paste clarity. Cereal Chemistry, 66, 173-182.

FAOSTAT. (2002), Database FAO. Food and Agriculture Organisation of the United Nations, Rome, Italy, 19.2. 
Galvez, F.C.F., Resurreccion, A.V.A. (1992), The effects of decortication and method of extraction on the physical and chemical properties of starch from mung bean (Vigna radiate (L.) wilczec). Journal of Food Processing and Preservation, 17, 93-107.

Ghiasi, K., Varriano-Marston, K., Hoseney, R. C. (1982), Gelatinization of wheat starch. II. Starchsurfactant interaction. Cereal Chemistry, 59, 86.

Gujska.E, Reinhard W. D., Khan K. (1994), Physicochemical Properties of Field pea, Pinto and Navy Bean Starches. Journal Food Science, 59, 634636.

Hallgren, L. (1985), Physical and structural properties of cereals, sorghum in particular in relation to milling methods and product use, Copenhagen-I: Carlsberg Research Laboratory, Technical University of Denmark.

Hizukuri, S., Takeda, Y., Shintozono, T., Abe, J., Ohtakara, A., Takeda, C., Suzuki, A. (1988), Structure and properties of water chestnut (Trapa natans L. var. bispinosa Makino) starch. Starch/ Starke, 40, 165-171.

Hoover, R., Sosulski, F. (1986), Effect of cross linking on functional properties of legume starches. Starch/Starke, 5, 149-155.

Javis, C.E., Walker, J.R.L. (1993), Simultaneous, rapid, spectrophotometric determination of total starch, amylose and amylopectin. Journal Science Food Agric. 63, 53-57.

Miles, M. J., Morris, V. J., Orford, P. D., Ring, S. G. (1985), The roles of amylase and amylopectin in the gelation and retrogradation of starch. Carbohydrate Research, 135, 271-281.

Moorthy, N. S. (2002), Physicochemical and functional properties of tropical tuber starches: A Review. Starch/Starke, 54, 559-592.
Morris, V.I. (1990), Starch gelation and retrogradation. Trends in Food Science and Technology, 7, 2-6.

Mua, J. P., Jackson, D. S. (1997), Relationships between functional attributes and molecular structures of amylose and amylopectin fractions of corn starch. Journal of Agricultural and Food Chemistry, 45, 3848-3854.

Murty, V.L.N., Choudhury, D., Bagehi, P. (1962), Physicochemical studies of water chestnut starch (Trapa bispinosa Roxb.). Can. J. Chem. 48, 2602265.

Sandhya Rani, M. R., Bhattacharaya, K. R. (1989), Rheology of riceflour pastes: effect of variety, concentration and temperature and time of cooking. Journal of Texture Studies, 20, 127-137.

Seetharaman, K., Tziotis, A., Borras, F., White, P. J., Ferrer, M., Robutti, J. (2001), Thermal and functional characterization of starch from Argentinean corn. Cereal Chemistry, 78, 379-386.

Swinkels, J. J. M. (1985), Sources of starch, its chemistry and physic. In G. M. Van Beynum and J. A. Roel (Eds.), Starch conversion technology (pp. 15-46). New York: Marcel Dekker.

Vanna, T., Khajee Boondee., Thanachan Mahawanich. (2004), Characterization of starch from water chestnut ( Trapa Bispinosa Roxb.). Journal of Food Biochemistry, 29, 337-348.

Wang, L. Z., White, P. J. (1994), Structure and physicochemical properties of starches from oats with different lipid content. Cereal Chemistry, 71, 443450 .

Received: February17, 2008; Revised: August 14, 2008; Accepted: October 01, 2009 